DOI: $10.17805 /$ trudy.2019.4.5

\title{
СТУДЕНТЫ ПОКОЛЕНИЯ Z: РЕАЛЬНОСТЬ И БУДУЩЕЕ
}

\author{
В. А. Захарова \\ Московский гуманитарный университет
}

Аннотация: В статье раскрывается сущность теории поколения, а также необходимость применения теории с целью построения успешного взаимодействия со студентами ХХІ века.

Ключевые слова: теория поколений; поколение Z; поколение X; клиповое мышление

\section{STUDENTS OF GENERATION Z: REALITY AND FUTURE}

\author{
V. A. Zakharova \\ Moscow University for the Humanities
}

\begin{abstract}
The article reveals the basic essentials of the generational theory as well as the need to apply the theory with the aim of creating successful interaction with 21st century students.
\end{abstract}

Keywords: generational theory; generation Z; generation X; clip thinking

Новые поколения студентов не похожи на предыдущие поколения никогда ранее студенчество не пользовалось такой обширной базой данных, как Интернет. Влияние мировой сети заметно во всех аспектах человеческой жизни, и, разумеется, вузовской системе образования невозможно игнорировать этот факт. Обучение обязано учитывать психологические законы познавательной деятельности учащегося (Мазилов, 2018). Исследования Университета Гавайи (UH), ставя своей миссией, высококачественное образование для учащихся, показывают, что сейчас необходимо изменить способы обучения, чтобы приспособиться к ценностям и стилям обучения этих новых учеников, в частности, представителям поколения Z. Методы обучения, курс, содержание и цели должны быть релевантными и привлекательными для этого нового поколения учащихся, если высшее учебное заведение своим приоритетом видит высококачественное образование для обучающихся. 
Научные труды Московского гуманитарного университета 2019 № 4

В данной статье показывается, что обучающиеся представители поколения $\mathrm{Z}$ имеют свои особенности, ценности и цели. Таким образом, изучая специфику представителей нового поколения, возможно, сделать методы традиционного преподавания более эффективными.

Создавая и улучшая эффективность системы образования, воспитания и социализации нового поколения, необходимо дать характеристику современному студенту на основании современных психологических исследований.

Сегодня есть несколько научных подходов к изучению теории поколений. Объектом исследований педагогов и психологов молодое поколение стало с конца XIX века. Ключевое значение имеют подходы Л. С. Выготского и Ж. Пиаже; свой вклад также внесли Б. Г. Ананьев, Г. С. Костюк, М. И. Лисина, А. А. Люблинская, А. В. Запорожец, Л. А. Венгер, П. Я. Гальперин. В России теорию поколений адаптировали социологи Ю. А. Левада В. В. Гаврилюк, Н. А. Трикоз и психологи Е. М. Шамис и А. Антипов.

У. Штраус и Н. Хоув в 1991 г. опубликовали книгу «Поколения. История Американского будущего. 1584-2069», которая была написана на основании исследований специалистов в областях экономики, психологии, социологии и политологии тридцати стран мира (Howe, Strauss, 1991). Они определяют поколение как совокупность всех людей, рожденных в конкретный временной период (примерно 20 лет), либо проживающих в одном историческом временном отрезке как минимум одну фазу жизни: детство, молодость, средний возраст или старость. По мнению исследователей, временной период в 20 лет - это единый исторический временной отрезок, наполненный событиями, в масштабах мира, страны и общества, которые оказывают основное влияние на формирование у людей знаний, навыков, моделей поведения, ключевых убеждений. Зная об опыте и особенностях, которые они разделяют со своими ровесниками, представители одного поколения разделяют и чувство принадлежности к этому поколению.

Ключевая позиция Хоува-Штрауса основана на утверждении, что особенности того или иного поколения базируются на ценностях, сформированных под влиянием внешних событий (Голубинская, 2016). С этим утверждением согласна и М. Р. Мирошкина, которая отмечает, что каждое поколение - участник исторических событий, значительно меняющих либо устои страны в целом, либо правила жизни в определенный период времени (Мирошкина, 2017). Однако, основываясь на промежуточных результатах комплексного междисциплинарного исследования «Цифровое поколение. Портрет в контексте образования», она предложила свой подход к пониманию российских поколений XXI в. (там же). В ее исследовании говорится, что в отличие от схемы смены поколений, представленной в 
классической теории У. Штрауса и Н. Хоува, траектория смены российских поколений XX-XXI вв. носит не поступательный, а дискретный характер.

Наименования поколений хоть и разнятся, но годы рождения практически идентичны (см. таб.).

Таблища. Сравнительная характеристика поколений Штрауса-Хоува и М. Р. Мирошкиной.

\begin{tabular}{|c|c|c|c|}
\hline $\begin{array}{c}\text { Основное название в } \\
\text { теории поколений } \\
\text { Штаруса-Хоува }\end{array}$ & $\begin{array}{c}\text { Годы } \\
\text { рождения }\end{array}$ & $\begin{array}{c}\text { Альтернативные } \\
\text { названия }\end{array}$ & $\begin{array}{c}\text { Годы } \\
\text { рождения }\end{array}$ \\
\hline Победители & $1903-1923$ & Поколение революции & $1903-1923$ \\
\hline Молчаливое & 1923-1943 & $\begin{array}{c}\text { Поколение победителей, поколение } \\
\text { оттепели }\end{array}$ & $1923-1940$ \\
\hline $\begin{array}{l}\text { Бейби-бумеры } \\
\text { (BВ) }\end{array}$ & 1944-1963 & $\begin{array}{c}\text { Первое послевоенное поколение, } \\
\text { поколение холодной войны }\end{array}$ & 1941-1964 \\
\hline $\mathrm{X}$ & 1964-1984 & $\begin{array}{c}\text { Последнее советское поколение, } \\
\text { поколение перестройки }\end{array}$ & $1965-1973$ \\
\hline Y & $1985-2003$ & Первое несоветское поколение & 1974-1985 \\
\hline $\mathrm{Z}$ & $2004-2024$ & $\begin{array}{l}\text { Цифровое поколение, } \\
\text { поколение «Путина» }\end{array}$ & 1986-2014 \\
\hline
\end{tabular}

Н. А Зайцева характеризует Поколения X и Z следующим образом. Поколение «Х» («Иксы») (1963-1982 гг. рождения) - поколение разгара «холодной войны». На время их формирования пришлись развал СССР, война в Афганистане и перестройка, распространение СПИДА и наркомании, экономические кризисы и дефолты. Признаки этого поколения - готовность к переменам и собственному изменению, понимание, что новые знания и навыки - не только признак личностного роста - но и способ выживания, прагматизм, осторожность и расчет на собственные силы. По мнению Зайцевой, своими основными ценностями представители поколения Х считают возможность выбирать из большого количества вариантов, а также гендерное равенство (Зайцева, 2015)

Время перестройки вынудило поколение X стать более гибкими в отношениях с людьми, а постоянный поиск работы родителями и их трудоголизм - развили в юных «Иксов» самостоятельность. Вырастая, они 
становились людьми, для которых характерны постоянная готовность к переменам, расчет только на собственные силы и собственный опыт. Лучшая работа для них, по их же собственному мнению - работа, позволяющая проявить творческие способности, гибкость и креативность мышления. При этом «Иксы» довольно циничны и прагматичны.

На наш взгляд, для понимания последнего советского поколения наиболее продуктивен подход антрополога А. Юрчака, который указывает, что неожиданность обвала системы, вместе с чувством удивления, ощущением нереальности происходящего и, возможно, чувством эйфории или, напротив, трагедии, которые ему сопутствовали, стала главным принципом формирования этого поколения (Юрчак, 2016).

Юрчак подчеркивает, что, с его точки зрения, последними истинно советскими людьми являются те, кто не просто успел родиться в той стране, а успел в ней повзрослеть и сформироваться как раз до начала ее неожиданного конца.

-Поколение «Z» («Зеты») - (2000-2020 гг. рождения) - рожденные в век цифровых технологий, представители поколения Z взаимодействуют с миром на принципиально другом уровне, не известном ранее: интернет неотъемлемая часть жизни, которая в той или иной мере включает в себя общение и досуг, учебу и работу. В этих условиях становление личности происходит при непосредственном и активном участии Интернета. Уникальность поколения формируется за счет существования в совершенно иных условиях развития и социализации.

- Как отмечают Дж. Пэлфри и К. Гассер, «Зеты» не делают различия между жизнью в Сети и вне ее, ибо не воспринимают свою идентичность в цифровом и реальном пространстве как нечто обособленное; считают, что их идентичность представлена сразу в нескольких пространствах (Пэлфри, Гассер, 2011). Это значит, что статус личности «Зета» и его значимость в Интернете - блогер, стример, эльф высокого ранга в игре - также важны, значимы и реальны, как и жизнь офлайн. Статус в Сети может сказываться в реальной жизни как на круг знакомств, доход и занятость так и на статус в жизни: высокоранговые пользователи Сети становятся известными в реальности; получают возможность в той или иной степени влияния на других людей. По мнению автора книг «Взросление в цифровом мире: Как сетевое поколение меняет мир» и «Викиномика. Как массовое сотрудничество изменяет все» Дж. Тапскотта, Интернет сформировал принципиально новую среду социальной идентификации, самовыражения и стиля жизни молодежи, которая носит двойственный характер (Тапскотт, Уильямс, 2008).

С одной стороны, Интернет коренным образом изменил соотношение 
частной и публичной сторон жизни: грань между ними стерта - через Сеть человек постоянно на связи со всем миром. С другой стороны - появилась возможность создания собственного стиля, который формируется под влиянием тенденций, распространенных в Сети. Это, в свою очередь, привело к появлению абсолютно новых путей идентификации личности: возрастает индивидуализация, концентрация личности на индивидуальном стиле жизни («личный бренд») (Линн, Ситкинс, 2014).

Дж. Тапскотт и Э. Уильямс говорят о том, что представители поколения Z не являются просто потребителями массовой культуры (Тапскотт, Уильямс, 2008). Они «проводят время в поиске, чтении, исследовании, идентификации, сотрудничестве и процессе организации. Интернет превращает жизнь в постоянное массовое сотрудничество, что безумно нравится этому поколению. Они даже не могут представить себе жизнь, в которой граждане не имеют инструментов для критического осмысления, обмена точками зрения, уточнения, идентификации или разоблачения обмана. Если их родители были пассивными получателями информации, молодые люди является активными создателями медийного контента и испытывают страсть к взаимодействию» (Дж. Тапскотт, 2009: 146).

Дж. Коатс, автор книги «Поколения и стили обучения», предлагает педагогам, работающим с поколением Z следующие «подсказки».

1) Молодые люди задаются вопросом «Зачем мне это надо?» и в этом ключе образование кажется им бессмысленным. Пример: зачем мне знать даты рождения и смерти классического автора (его биографию, его произведения), если есть Википедия? Пара кликов - и информация на экране. Может, стоит объяснить молодым людям, что дело не столько в запоминании дат, а в тренировке памяти? И что ознакомление с произведением автора, его анализ и пересказ - это тренировка образного мышления, ораторского мастерства, навыков логического повествования, расширение словарного запаса? А может, и самим преподавателям стоит задуматься - что стоит за классическим преподаванием - механическое заучивание, приводящее к тому, что половина информации после учебного заведения у человека выветривается из головы навсегда - или интерес, побуждающий человека за цифрами дат рождения и смерти видеть больше - эпоху, события, людей? Коатс убеждена, что создание учебных планов, в центре внимания которых стоит возможность обучающегося эффективно действовать с миром ключ к успеху в XXI столетии (Коатс, 2011).

2) Кооперация вместо конкуренции. «Зеты» умеют и любят сотрудничать, для них очевидна ценность продуктивного взаимодействия, а оценки служат подтверждением этому. Поэтому «Зеты» очень внимательно отно- 
Научные труды Московского гуманитарного университета 2019 № 4

сятся к поощрениям и наградам, и здесь есть их определенная «ахиллесова пята» - завышенные ожидания от мира, что тот будет благодарен им за любой чих. Хвалите, но не перехваливайте. Давайте им свободу поиска, но не пускайте на самотек - «Зеты» быстро теряют интерес к тому, что «не получается».

Исследователи отмечают, что «Зетов» отличает от предыдущих поколений мышление, основанное на совершенно иных категориях (Сапа, 2014). Образ их мыслей отличается фрагментарностью, а иногда и поверхностностью.

Особенностью познавательной сферы поколения Z необходимо назвать клиповость мышления. Термин «клиповое мышление»ввел Ф. И. Гиренок (Гиренок, 1995). Клиповое мышление характеризуется выжимкой: не надо читать всю «Войну и мир», если можно прочесть аннотацию или краткое содержание. Длинный текст утомителен, лекция скучна - нужны тезисы, краткое изложение. Клиповое мышление понимается как процесс отражения множества разнообразных свойств объектов, без учета связей между ними, характеризующийся фрагментарностью информационного потока, алогичностью, полной разнородностью поступающей информации, высокой скоростью переключения между частями, фрагментами информации, отсутствием целостной картины восприятия окружающего мира. Клипововое мышление формируется при постоянном взаимодействии с Интернет контентом. Это особенность мышления ведет к неспособности многих людей системно воспринимать информацию, системно мыслить и, соответственно, излагать свои мысли. Часто после произнесенной (написанной) фразы, человек не пытается понять ее целиком, а выхватывает кусок-раздражитель, на который у него уже готов заранее ответ. Человек привыкает к постоянному мельтешению, сменам картинок и образов и уже не может воспринимать классические ленты, музыку, литературу - все, что требует сосредоточенности и умения делать выводы. Педагогам необходимо найти пути и возможности грамотного его применения как в образовательном процессе (Митягина, Долгополова, 2009).

Клиповое мышление обладает не только недостатками - это просто развитие одних когнитивных навыков за счет других. Это феномен, присущий поколению Z, воспитанному в эпоху бума компьютерных и коммуникационных технологий. Дети интернет-поколения одновременно могут слушать музыку, общаться в чате, бродить по сети, редактировать фотографии, делая при этом уроки. Но, разумеется, платой за многозадачность становятся рассеянность, гиперактивность, дефицит внимания и предпочтение визуальных символов логике и углублению в текст. 
Личностные особенностями поколения Z проявляются в их крайних проявлениях, в форме определенных психологических синдромов.

Вторая черта «поколения будущего» - склонность к аутизации. Речь идет об аутизме не в виде расстройства (хотя детей-аутистов становится все больше), а о доклинических формах аутизма, рассматриваемых как крайнее проявление тренда эволюции человечества. Аутизация, как способ взаимодействия с миром людей, с детства погруженных в себя и неспособных общаться с окружающими, выступает как защита от проблем современного образа жизни, как способ отгораживания от мира, по сути - способ десоциализации. Психологический диагноз нового поколения - интровертированный индивидуализм (Сапа, 2015).

Поколение Z в России гораздо больше соотносится с поколением Z в других странах. Если для поколения X в нашей стране были присущи яркие особенности, вызванные глобальной исторической переменой - развалом CCCP, то для Z всеохватывающее влияние интернета характерно и для нашей страны, и для мира в целом.

Результаты мониторинга московского информационного-образовательного пространства, проведенного в 2013 г., позволили сделать вывод о том, что в современном мире практически сформирована иная жизненная среда - цифровое биосоциальное пространство, когда виртуальное пространство есть продолжение физического и социального (Мирошкина, 2017). Это значит, что российское молодое поколение, также, как и западное, ждут социальная и культурная трансформации, обусловленные ростом интернет-трафика и возрастающим участием человека в формировании информационного социума. Это подтверждает отчет компании Cisco «Наглядный индекс развития сетевых технологий: полный прогноз на период 2015-2020 гг.», согласно которому к 2020 г. произойдет утроение IP-трафика (Наглядный индекс ... , 2016). Это значит, что весь социум - и российский, и мировой - будет связан единой информационной интернет-системой, влияющей на все сферы жизни человека, поколения и общества в целом.

Для успешного взаимодействия с поколением $\mathrm{Z}$ нужно не просто учитывать их особенности - необходимо изменять сами принципы взаимоотношений. Интернет сделал молодых Z-ов практически независимыми от взрослых в получении интересующих их сведений и знаний (Мирошкина, 2017). Образовательная среда должна становиться не просто интернетактивной - она должна быть привлекательной для юзеров. В книге «Физика будущего» М. Каку делая предположение об образовании будущего, говорит о глобальных изменениях в самих принципах образования. По мнению ученого, учеба уже не будет базироваться на запоминании, и учащиеся бу- 
дут заниматься самообразованием, ибо будут четко понимать, какие именно знания им необходимы. Обучение будет подстраиваться под конкретную личность, независимо от того. Сколько ему лет - шесть или шестьдесят. Таких разработок уже очень много, и они успешно внедряются (Каку, 2012).

\section{СПИСОК ЛИТЕРАТУРЫ}

Гиренок, Ф. И. (1995) Метафизика пата. М. : Лабиринт.

Голубинская А.В. (2016) К вопросу о поколенной модели Хоува-Штрауса // Международный журнал гуманитарных и естественных наук. № 1. C. 98-101.

Зайцева, Н. А. (2015) Теория поколений: мы разные или одинаковые? // Российские регионы: взгляд в будущее. № 2 (2). С. 220-236.

Каку, М. (2012) Физика будущего: пер. с англ. М. : Альпина нон-фикшн. $583 \mathrm{c.}$

Коатс, Дж. (2011) Поколения и стили обучения : пер. с англ. Л. Е. Колбачева. М. : Межгосударственная ассоциация последипломного образования. $121 \mathrm{c}$.

Линн, Л., Ситкинс, П. (2014) Личный бренд: позаботьтесь о вашей репутации прежде, чем это сделают другие / пер. с англ. Е. Никитиной. М.: Азбука-Аттикус; Азбука Бизнес. 218 с.

Мазилов, В. А. (2018) Инновации в современном образовании: психология vs педагогика//Ярославский педагогический вестник. № 1. С. 8-22.

Мирошкина, М. Р. (2017) Интерпретации теории поколений в контексте российского образования // Ярославский педагогический вестник. № 6 . С. 30-35.

Митягина, Е. В., Долгополова, Н. С. (2009) «Клиповое сознание» молодежи в современном информационном обществе // Вестник Нижегородского университета им. Н. И. Лобачевского. Серия Социальные науки. № 3 (15). С. 53-59.

Пэлфри, Дж., Гассер, У. (2011) Дети цифровой эры. М. : Эксмо-Пресс.

Сапа, А. В. (2014) Люди нового тысячелетия или поколение Next // Инновационные проекты и программы в образовании. № 2 С. 24-31.

Сапа, А. В. (2015) Поколение Z - поколение эпохи ФГОС // Психолог в школе. № 8 (20). С. 2-9.

Тапскотт, Дж., Уильямс, Э. (2008) Викиномика. Как массовое сотрудничество изменяет все. М. : BestBusinessBooks.

Юрчак, А. (2016) Это было навсегда, пока не кончилось. Последнее советское поколение. М.: Новое литературное обозрение. 664 с. 
Наглядный индекс развития сетевых технологий: полный прогноз на период 2015-2020 гг. (2016) // Технологии и средства связи. № 3. С. 50-51.

Howe, N., Strauss, W. (1991) Generations: The History of America's Future, 1584 to 2069. NewYork: William Morrow \& Company.

Дата поступления: 15.08.2019 г.

Захарова Валерия Александровна - магистрант кафедры педагогики и психологии высшей школы Московского гуманитарного университета. Адрес: 111395, Россия, г. Москва, ул. Юности, д. 5 . Тел.: +7 (499) 374-74-59. Эл. адрес: silverdrakonic@mail.ru. Научный руководитель - д-р пед. н., проф. В. А. Ситаров.

Zakharova Valeriya Aleksandrovna, Graduate Student, Department of Pedagogy and Psychology of Higher Education, Moscow University for the Humanities. Postal address: 5, Yunosti St., Moscow, Russian Federation, 111395. Tel.: +7 (499) 374-74-59. E-mail: silverdrakonic@mail.ru. Scientific Adviser V. A. Sitarov, Doctor of Pedagogy, Professor.

\section{Для цитирования:}

Захарова В. А. Студенты поколения Z: реальность и будущее [Электронный ресурс] // Научные труды Московского гуманитарного университета. 2019. № 4. URL: http:// journals.mosgu.ru/trudy/article/view/1013 (дата обращения: дд.мм.гг.). DOI: 10.17805/ trudy.2019.4.5 